\title{
BMJ Open Mass media representation of suicide in a high suicide state in India: an epidemiological comparison with suicide deaths in the population
}

\author{
Gregory Armstrong, ${ }^{\oplus 1}$ Lakshmi Vijayakumar, ${ }^{2}$ Jane Pirkis, ${ }^{3}$ Mala Jayaseelan, ${ }^{2}$ \\ Anish Cherian, ${ }^{4}$ Jane Brandt Soerensen, ${ }^{5}$ Vikas Arya, ${ }^{\bullet} 6$ \\ Thomas Niederkrotenthaler ${ }^{7}$
}

To cite: Armstrong G, Vijayakumar L, Pirkis J, et al. Mass media representation of suicide in a high suicide state in India: an epidemiological comparison with suicide deaths in the population. BMJ Open 2019;9:e030836. doi:10.1136/ bmjopen-2019-030836

- Prepublication history and additional material for this paper are available online. To view these files, please visit the journal online (http://dx.doi. org/10.1136/bmjopen-2019030836).

Received 3 April 2019 Revised 25 June 2019 Accepted 3 July 2019

Check for updates

(C) Author(s) (or their employer(s)) 2019. Re-use permitted under CC BY-NC. No commercial re-use. See rights and permissions. Published by BMJ.

For numbered affiliations see end of article.

Correspondence to Dr Gregory Armstrong; g.armstrong@unimelb.edu.au

\section{ABSTRACT}

Objectives Suicide rates in India are among the highest in the world, equating to over 200000 suicides annually. Reports of suicides are a routine feature in major newspapers in India, and reporters may selectively present 'newsworthy' suicide stories. The aim of this paper was to systematically investigate whether mass media reports of suicides reflect the epidemiological data on suicide in a high suicide state in India. Design We undertook a content analysis study to extract sociodemographic data on suicides reported among nine of the most highly read daily newspapers in the high suicide southern state of Tamil Nadu between June and December 2016. A total of 1258 newspaper articles were retrieved containing reports on 1631 suicides. Two-tailed binomial tests on aggregate frequencies assessed whether the sociodemographic characteristics of suicides in the newspaper articles were different to the population suicide statistics for Tamil Nadu.

Results We identified some statistically significant discrepancies between suicide characteristics in the population and the media. Suicides involving females $(p<0.001)$, those aged under 30 years $(p<0.001)$, separated or widowed males $(p<0.001)$, unmarried females $(p<0.001)$, those using methods with a higher case fatality rate (ie, hanging $(p<0.001)$, jumping off high structures $(p<0.001)$ and coming under vehicles $(p<0.001)$ and those who were students $(p<0.001)$ or working in the agricultural sector $(p<0.001)$ were significantly over-reported relative to their occurrence in the broader population. Suicides involving men $(p<0.001)$, those aged over 30 years and above $(p<0.001)$, those who were married and suicides by poisoning $(p<0.001)$ were significantly under-reported relative to their occurrence in the broader population.

Conclusions The suicide characteristics in the print media were not entirely representative of suicides in the broader Tamil Nadu population, which may lead the general public to develop misunderstandings about suicide in their state. The discrepancies we identified will inform tailored suicide prevention education for media professionals.

\section{BACKGROUND}

Southeast Asia accounts for roughly $40 \%$ of the estimated 800000 suicides that occur
Strengths and limitations of this study

- Suicides are a routine feature in major newspapers in India, and this is the first study to examine whether these media reports of suicides reflect the epidemiological data on suicide in India.

- We followed nine major newspapers over 7 months and collected a large sample of 1631 media reports of suicides.

- We only looked at printed newspapers in one state with a high suicide rate; with further funding, it would be desirable to examine media reports by other forms of mass and social media across a broader range of states.

- A large proportion of suicides are not captured in the official suicide statistics in India, due to a sole reliance on police data and the lack of a comprehensive and reliable vital registration system. Given both the official statistics and the media reports used in this study are based on police reports of suicide, we expect that this will have a negligible effect on the comparisons made in our study.

- While our findings provide some epidemiological clues as to the decisions made by media professionals in choosing whether to report on a suicide, further qualitative research with media professionals is required to better understand the decision-making process and any biases that may be involved.

each year globally. ${ }^{1}$ Suicide rates in India are among the highest in the world with the most recent suicide death rate estimates ranging between 18 and 21 deaths per 100000 population (compared with the global average of $11 / 100000)$. This equates to an estimated 230000-250000 suicide deaths annually with far-reaching social, emotional and economic consequences. ${ }^{12}$ A public health approach to suicide is gaining momentum in India with calls for the development of national and state-level suicide prevention strategies, including the development of media 
guidelines to improve mass and social media coverage of suicides. ${ }^{3}$

One of the few recommended suicide prevention strategies at the population level is responsible media reporting of suicides ${ }^{4-6}$ based on evidence around copycat suicides, dissemination of suicide methods and behaviours and the imperative to deliver tailored suicide prevention messaging in media content. ${ }^{7-12}$ Consequently, the WHO recommends that public health specialists should engage with media professionals to limit irresponsible media coverage (eg, reports that sensationalise suicide) and to promote coverage that educates the public about suicide. $^{13}$

The manner by which the mass media communicates with the Indian public on the topic of suicide in India has thus far gone without sufficient inquiry. ${ }^{14}$ Our own recent research into print media portrayals of suicide in India observed that explicit suicide reports are a routine feature and that potentially harmful reporting practices are common. ${ }^{15}$ For example, a detailed suicide method was reported in $43.3 \%$ of articles. Given that there are few alternative sources of publicly disseminated information on suicide in India, as the suicide prevention sector is relatively under-resourced, these mass media portrayals of suicide are quite possibly playing a critical role in shaping and reflecting public attitudes and behaviours in relation to suicide.

Researchers have long recognised the disparity between the epidemiological data on suicide in the population and the stories selectively presented for mass media reports. ${ }^{16}$ In suicide prevention, there is a major focus on disseminating knowledge on the risk factors and the complex multilayered context for suicide. ${ }^{6}$ This can be at odds with media preferences for newsworthy stories that are atypical or that play to broader social narratives of interest to readers. Hence, one important area of enquiry for suicide prevention is to better understand what kinds of suicides media broadcast to the public to shed light on possible misunderstandings of the epidemiological realities that can inform media training and engagement strategies. Very few studies have examined which suicides tend to feature in the media. Those that have, found that the mass media selectively present newsworthy suicide stories that do not reflect the broader array of suicides in the population, ${ }^{17-20}$ which can carry profound implications for the social and political responses to suicide.

This phenomenon is yet to be studied in India. This paper seeks to address this gap in the literature by comparing the characteristics of suicides in print media reports in India against the characteristics of suicides in the population. Due to the large number of languages across India and the prohibitive level of resources required to fund a study with a broad national spread of newspapers published in a range of languages, we elected to undertake a comprehensive study of newspaper reporting in one state. We chose the southern state of Tamil Nadu (population $=72$ million), which consistently has one of the highest suicide rates in India (22.8/100 000) equating to 15777 recorded suicides in 2015 , over 40 suicides per day. ${ }^{21}$ The approach of focusing on one state allows us to comprehensively track changes in media reporting in this state following upcoming efforts to engage with the media on this topic.

\section{METHODS}

As part of the Suicide in the Indian Media project, ${ }^{15}$ we undertook a content analysis study of articles reporting suicide-related news in 9 of the 10 most highly read vernacular and English-language daily newspapers in Tamil Nadu over the 7-month period between 1 June and 31 December 2016. The nine newspapers collectively have an estimated average daily readership of over 16000000 people in Tamil Nadu alone. ${ }^{22}$ Five of the nine newspapers under review are in the top 20 most circulated daily newspapers in the country, ${ }^{23}$ giving the findings relevance beyond Tamil Nadu. We previously published research from this content analysis study where we assessed the quality of newspaper reporting of suicide-related news against WHO suicide reporting guidelines. ${ }^{1315}$

To source the articles, the hard copies of all 1926 (9 newspapers $\times 214$ days) editions of the nine newspapers during the study period were hand searched by three trained research assistants (psychologists), allowing us to include several newspapers that did not have a strong online presence. Our search yielded 1258 articles containing reports on 1631 suicides; the vast majority of these suicides were of people from Tamil Nadu (84.0\%, $\mathrm{n}=1371$ ), while the remainder were largely of people from elsewhere in India $(14.5 \%, \mathrm{n}=236)$ or from other countries $(1.1 \%, \mathrm{n}=18)$, with location unable to be determined in $0.4 \% \quad(n=6)$ of the media reports. We elected to retain all suicides in our primary analyses, regardless of the location of the deceased, as these reports will still influence the public's impressions of who is affected by suicide; secondary analyses will exclusively examine suicides of people from Tamil Nadu. We excluded articles where suicide was only mentioned briefly (ie, $<50 \%$ of the article) and articles with a focus on terrorist-related suicide bombings or euthanasia.

A bilingual psychologist and researcher (MPsych and MPhil) extracted data on gender, age, marital status, suicide method and occupational status for each suicide. We compared the data extracted from the newspaper articles with the characteristics of suicides in the Tamil Nadu population suicide statistics found in the Accidental Death \& Suicides in India report for 2015 published by the National Crime Records Bureau (NCRB). ${ }^{21}$

Comparing occupational status between the two data sets was complicated by the use of broad category descriptors in the NCRB data (eg, 'professionals/salaried persons') that were not possible to reproduce. However, there were two occupational categories that were distinct enough to legitimately reproduce and examine: 'students' and 'persons engaged in the farming sector'. Both are occupational groups that have been of significant interest to 
suicide prevention in India and would resonate strongly with the public when discussing the topic of suicide. ${ }^{24}{ }^{25}$

We disaggregated the data by gender, and in doing so, we excluded suicides of Hijra and transgender people due to the very small numbers of such cases; there were 13 reports of suicide deceased who were Hijra/transgender in the newspaper articles and two such suicide deceased in the official suicide records for Tamil Nadu.

Two-tailed binomial tests on aggregate frequencies were used in Stata (command 'prtesti') to assess whether the distribution of the characteristics of suicides in the newspaper articles was different to their distribution in the population suicide statistics for Tamil Nadu. This analysis approach has been used previously by a similar media study in Austria. ${ }^{17}$ Not all media reports contained data on all the variables we analysed, so percentages were calculated based on data for those individuals for whom these characteristics were reported in the article.

\section{Patient and public involvement}

Patients and the public were not involved in the design or planning of this study.

\section{RESULTS}

Binomial tests showed that female suicides were over-reported relative to their occurrence in the broader population of suicides, comprising $45.3 \%$ (729/1610) of suicides in newspaper reports compared with $32.0 \%$ $(\mathrm{n}=5041 / 15775)$ of suicides in the official suicide statistics $(\mathrm{p}<0.001)$ (see figure 1$)$. While newspapers covered a significantly higher percentage of female suicides, this was not the case across all age groups. There was no statistically significant difference in the $<18$ years age group, and we observed the reverse pattern in the $60+$ years age group, such that female suicides were significantly under-reported.

Binomial tests showed that the suicides of those aged less than 30 years were over-reported relative to their occurrence in the broader population (see table 1). Conversely,

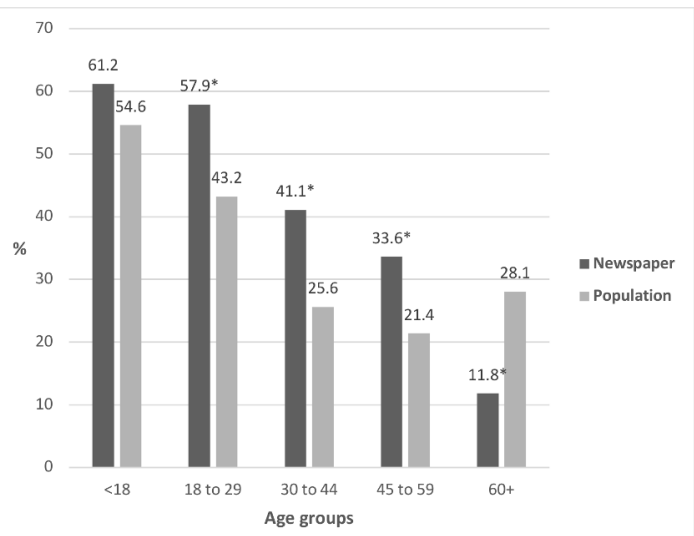

$*<0.05$, based on two-sided binomial tests within each age group to calculate if the proportion of suicide deceased in the newspaper articles that were female was different to that in the official suicide statistics

Figure 1 Comparing the proportion of female decedents in newspaper suicide reports versus the population suicide statistics for Tamil Nadu. the suicides of those aged 30 years or older were under-reported. The suicides of those who were unmarried, separated and widowed were over-reported, while the suicides of those who were married were under-reported. The gender stratification of these marital status results highlighted a gender-based difference. Suicides among separated and widowed men were over-reported, while it was the suicides of unmarried women that were over-reported; the suicides of those who were married were under-reported in both men and women.

The suicides of students and those engaged in the farming sector were over-reported relative to their occurrence in the broader population (see figure 2). Students comprised $15.6 \%(255 / 1631)$ of all suicides in newspaper reports compared with $6.1 \%(955 / 15775)$ of suicides in the official suicide statistics $(\mathrm{p}<0.001)$. People engaged in the farming sector comprised $6.3 \%$ (102/1631) of all suicides in newspaper reports compared with $3.8 \%$ $(606 / 15775)$ of suicides in the official suicide statistics $(\mathrm{p}<0.001)$. Conversely, the suicides of females in the agricultural sector were under-represented in media reports.

Deaths involving hanging, coming under vehicle/train, jumping off building/structure and self-inflicted injury such as a knife wound were over-reported, while suicides by poisoning were under-reported (see table 1 ).

Secondary analyses were undertaken, only including media reports of suicides of people from Tamil Nadu, to examine if our findings were confounded by media reports of suicides of people from outside Tamil Nadu. The results are consistent with the primary analyses (see online supplementary file 1 ).

\section{DISCUSSION}

The present study identified substantial disparities between suicide characteristics in the population and the media. Suicides involving women, those aged under 30 years, separated or widowed men, unmarried women and those using lethal methods (other than pesticides) were significantly over-reported relative to their occurrence in the broader population. The suicides of people from the occupational groups of students or persons engaged in the agricultural sector were also over-reported.

An important finding was that female suicides were significantly over-represented, relative to their occurrence in the population. This finding appears to be unique to India and is in stark contrast to what has been observed elsewhere. No under-reporting or over-reporting was observed in Australia ${ }^{19}$ or Austria ${ }^{17}$ based on gender. However, in the Chinese settings of Guangzhou and Taiwan, female suicides have been observed to be under-reported, ${ }^{20}$ the opposite pattern to our findings. The authors posited that, in traditional Chinese societies, women can be stereotyped as being more emotional or hysterical, and more prone to suicide. Such that, they felt media professionals may perceive the suicide deaths of men to be more unusual and thus newsworthy. 


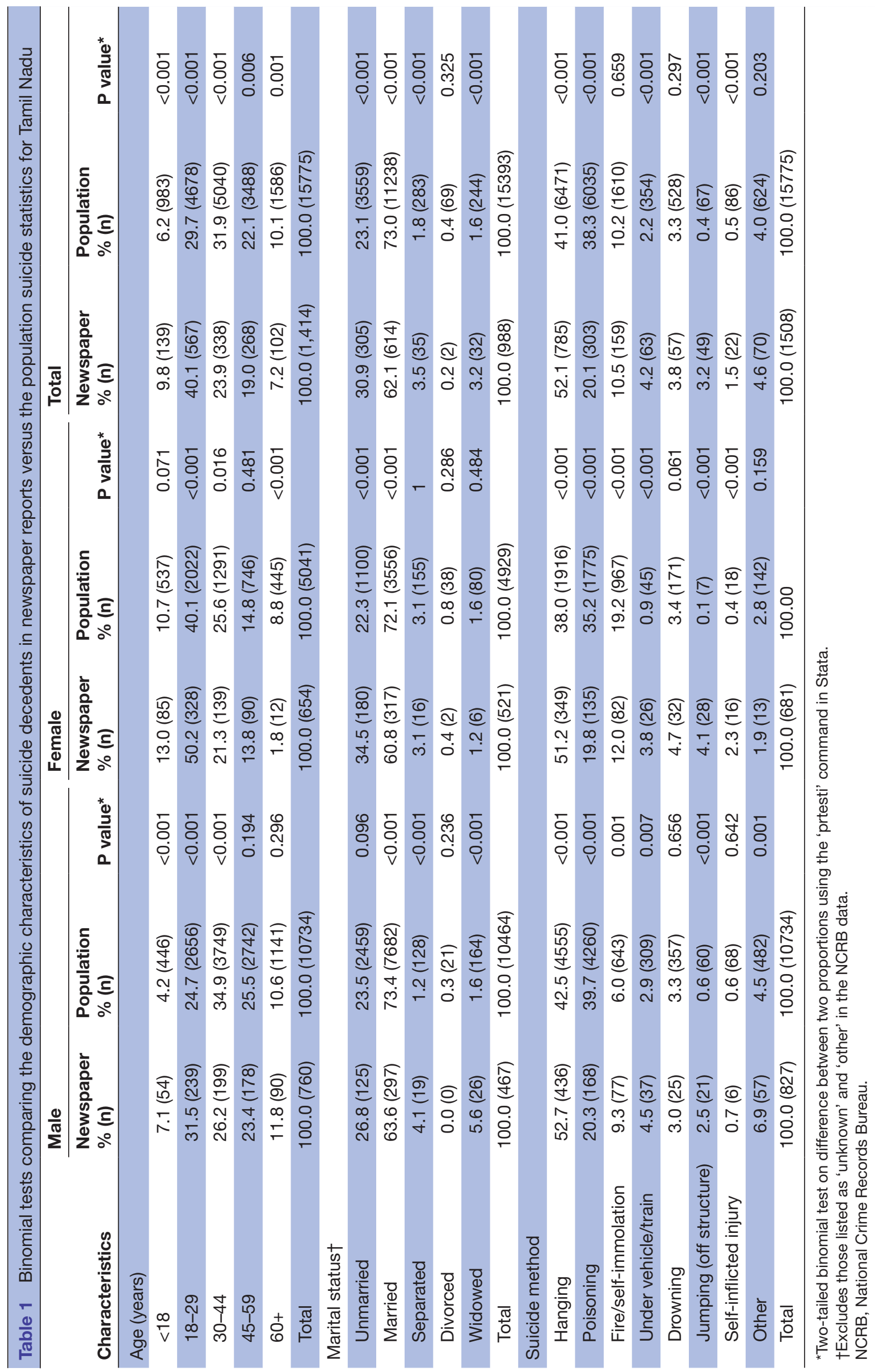




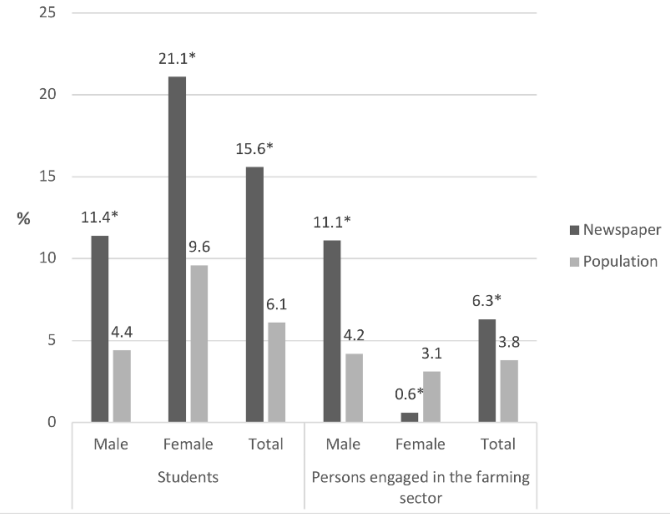

Note: The occupational categories of 'student' and 'persons engaged in the farming sector' were the only categories in the official statistics that were distinct enough to compare to the data we extracted from newspaper reports. Other occupational categories in the official suicide statistics (e.g. 'professionals/salaried persons') were too broad to be reproduced. $*<0.05$, based on two-sided binomial tests within each age group to calculate if the proportion of suicide deceased in the

Figure 2 Comparing the proportions of selected occupational groups of suicide decedents in newspaper reports versus the population suicide statistics for Tamil Nadu.

In India, the female suicide rate is among the highest in the world and is nearly three times higher than the rate expected globally for countries at similar levels of Socio-Demographic Index. ${ }^{2}$ This well-documented fact about suicide in India could possibly permeate the minds of media professionals, who may then give greater emphasis to the plight of women who take their lives. Notwithstanding this, it is also likely that there are some other reasons media professionals decide that the suicides of women are more newsworthy. Based on our anecdotal conversations with media professionals, we speculate that female suicides may also be perceived by media professionals to generate a greater empathic response among readers of newspapers in India. Stories of the suicides of females may align with paternalistic narratives about the risks to women in Indian society and the family and collective responsibility to protect them. ${ }^{26}$

We also observed an under-reporting of suicides of married men and women. Moreover, we observed that, among female suicides, there was an over-reporting of suicides among those who were unmarried. This was quite distinct from what was observed among male suicides, where suicides by separated or widowed men were over-reported in the newspapers. It is unclear why there is an apparent media preference for stories of unmarried women and separated or widowed men, nor what cultural scripts or narratives this may align with. Marriage and family are at the core of the social fabric in India, ${ }^{27}$ and family is the main source of welfare protections. We speculate that risks associated with being outside of the institution of marriage may be being emphasised by media professionals through their selection of suicide stories pertaining to people whose marriage has been lost or who are yet to enter marriage. Through this under-reporting of suicides of married people, these media reports may actually be giving an incorrect signal to the population with regard to any suicide prevention protections that may be assumed to be gained from being married. It is important to note that while marriage is typically understood to protect against suicide, particularly for men, based on findings from studies in Western settings, ${ }^{28}$ this is not the case in India. Research undertaken in India yields mixed findings regarding the relationship between marital status and suicide for both men and women, suggesting that either marriage is not a protective factor for suicide, or indeed that the risk of suicide is higher among those who are married. ${ }^{29}{ }^{30}$ This epidemiological reality regarding marriage and suicide may conflict with narratives in India that locate 'the family' as the main source of social protections. Clearly this is speculation, and so qualitative research with media professionals is required to better understand the phenomenon of the influential role of gender and marital status in the perceived newsworthiness of suicide deaths. We note, though, that even such qualitative interviews may find it hard to unravel what may be unconscious and deeply culturally embedded biases among media professionals.

Our findings suggest that the suicides of younger persons aged $<30$ years were considered to be more newsworthy than the suicide deaths of persons aged 30 years and older. This finding is largely consistent with research from Australia, ${ }^{19}$ Austria ${ }^{17}$ and China. ${ }^{20}$ It has been posited that youth suicides may be considered more newsworthy; that is, the death of a youth with their life ahead of them carries a sensational undertone that may grab the reader's attention. ${ }^{20}$ Suicide is also the leading cause of death among youth in India aged 15-29 years, and greater than $70 \%$ of female suicide deaths and $50 \%$ of male suicide deaths are in this age group. ${ }^{2}$ Thus, it is possible that media professionals may be attempting to give such suicide deaths greater emphasis without being aware that they may in turn be overlooking the issue of suicide among older aged people, also a high-risk period for both men and women in India. ${ }^{2}$

Our findings also revealed that the suicides of students and people engaged in the agricultural sector were significantly over-represented, relative to their occurrence in the population. This finding was not surprising, given that both occupational groups are of significant interest to the public discourse and narratives around suicide in India. ${ }^{24}$ Media houses would be aware that reports on such deaths would resonate strongly with readers. Student suicides are a major and topical policy issue in India, frequently located within discussions around the fierce competition for student places and an accompanying intensity of exam pressure. ${ }^{31}$ Reporting on this issue will likely be of great interest to parents, who may carry a level of fear around this happening to their own children. Farmer suicides are highly politicised in India and have been the subject of numerous government commissions and policy dialogues. This has largely been with a focus on issues around the high levels of indebtedness among farmers, a decline in secure institutional credit, water scarcity, trade liberalisation and a considerable vulnerability to 'crop failure'. ${ }^{32}$ Farmer suicide deaths have been 
described as 'public deaths', due to the perception that they receive sensational coverage by the mass media. ${ }^{33}$

Finally, suicides by particular methods also appeared to attract more media attention. Deaths involving hanging, jumping and coming under vehicle/train were over-represented in media reports, while suicides by poisoning were under-represented. One interpretation of this finding is that media may be attracted to reporting on suicides using methods with a higher degree of lethality, given that these have been observed to have a high case fatality rate. ${ }^{34}$ Deaths involving self-inflicted injuries (eg, knife wound) were also over-reported, even though this method does not have a high case fatality rate, indicating that newspaper reporters may also have an interest in particular suicide methods where it is easy for them to construct a graphic visual that may attract the attention of the reader. The under-reporting of poisoning suicide deaths is also an interesting finding. While the ingestion of medical drugs typically has a low case fatality rate, ${ }^{34}$ the ingestion of pesticides, a common suicide method in India and elsewhere in South Asia, ${ }^{35}$ has a high case fatality rate and is a major contributor to high suicide rates in this region. ${ }^{36} 37$

These findings have important implications for suicide prevention. While the mass media are a powerful resource for educating the public about suicide, the general public may develop misunderstandings about suicide that are caused by media misrepresentations. For example, Till $e t$ $a l^{38}$ observed that the consumption of tabloid newspapers in Austria for daily information appeared to be an independent factor in the endorsement of misconceptions and myths about suicide. While we did not assess the articles for suicide myths, we did observe substantial disparities between suicide characteristics in the population and the media. Strong biases towards reporting particular types of suicide deaths may result in social and political responses to suicide that are not based on the epidemiological data. For instance, if media reports are overly biased towards the coverage of female suicides, youth suicides, suicides among particular occupational groups or particularly graphic or more lethal suicide methods, this may inadvertently affect suicide prevention funding allocations, public perceptions about who is most at risk of suicide and the method they may use, among other possible consequences.

The study has several limitations that are worth noting. First, we compared data from media reports collected in 2016 against the official suicide statistics for 2015. While these are two different time periods, it is the most recently available suicide statistics for India, and we expect a high degree of stability between the 2015 and 2016 data. We compared the official suicide statistics for 2015 against that for 2014 and 2013, and we observed a high degree of stability in the data; for example, the suicide rate for Tamil Nadu was 22.8 in 2015 and 23.4 in 2014 , and $29.7 \%$ and $30.7 \%$ of suicide deaths were people aged 18-29 years in 2015 and 2013, respectively. Second, there is a high level of under-reporting of suicide in India.
Given both the official statistics and the media reports are based on police reports of suicide, we expect that this will have a negligible effect on the comparisons made in our study. Third, while our findings provide some clues as to the decisions made by media professionals in choosing whether to report on a suicide, we cannot speak definitively about the decision-making process and any biases that may be involved. We are currently undertaking qualitative research with media professionals to better understand this phenomenon. ${ }^{39}$ Fourth, we were only able to examine the over-representation or under-representation of two occupational categories that we could meaningfully reproduce. There are several additional occupational categories that would have been interesting to examine; for example, 'housewives' comprised $53 \%$ of female suicide deaths in the 2015 official suicide statistics, yet this occupational information or the specific term was rarely communicated in media reports. Finally, we only examined newspaper reports in one southern state of India where the suicide rate is substantially higher than the national average. It is possible that our findings do not reflect newspaper coverage of suicide in other states of India, particularly those with a lower suicide rate where mass media reports of suicides may be less common. Future research should examine reports in other states as well as reports in other forms of mass and social media.

\section{CONCLUSION}

The suicide characteristics in the print media in Tamil Nadu were not entirely representative of suicides in the broader population. A moderately skewed picture of reality is being presented to the community, which may lead the general public to develop misunderstandings about suicide in their state. In particular, suicides involving females, those aged under 29 years, separated or widowed males, unmarried females, those using methods with a higher case fatality rate and those who were students or working in the agricultural sector were significantly over-reported relative to their occurrence in the broader population. Conversely, suicides involving males, those aged over 30 years and above, those who were married and suicides by poisoning were significantly under-reported relative to their occurrence in the broader population. The discrepancies we identified will inform tailored suicide prevention education for media professionals.

\section{Author affiliations}

${ }^{1}$ Nossal Institute for Global Health, Melbourne School of Population and Global Health, The University of Melbourne, Melbourne, Victoria, Australia

${ }^{2}$ Department of Psychiatry, Voluntary Health Services Hospital, Chennai, Tamil Nadu, India

${ }^{3}$ Centre for Mental Health, Melbourne School of Population Health, University of Melbourne, Melbourne, Australia

${ }^{4}$ Department of Psychiatric Social Work, National Institute of Mental Health and Neuro Sciences, Bangalore, Karnataka, India

${ }^{5}$ Department of Public Health, Kobenhavns Universitet, Kobenhavns, Denmark

${ }^{6}$ Translational Health Research Institute (THRI), Western Sydney University, Sydney, New South Wales, Australia 
${ }^{7}$ Center for Public Health, Department of General Practice and Family Medicine, Medical University of Vienna, Vienna, Austria

Acknowledgements We would like to thank Ms Asha Ramia Veeraraghavachary, Mrs Thangaraj Fathima Roseline and Ms Nivetha Vincent from Voluntary Health Services in Chennai for their thorough work in hand searching the nine newspapers for the relevant articles for this study.

Contributors GA designed the study, supervised the data collection and led the data analyses and drafting of the manuscript. LV and TN supported the design of the study. MJ implemented data collection. LV, JP, MJ, AC, JBS, VA and TN all contributed to the data analysis plan, interpretation of the results and the development of the final manuscript.

Funding The lead author is funded by an Early Career Fellowship from the National Health and Medical Research Council in Australia (GNT1138096). This study was funded by Early Career Researcher Awards from The Society for Mental Health Research and The University of Melbourne.

Competing interests None declared.

Ethics approval The data used in this study are from publicly available documents. Nonetheless, we obtained ethics approvals from the Human Ethics Advisory Group at The University of Melbourne in Australia (ID: 1646245.1).

Provenance and peer review Not commissioned; externally peer reviewed. Data sharing statement Data are available on reasonable request.

Open access This is an open access article distributed in accordance with the Creative Commons Attribution Non Commercial (CC BY-NC 4.0) license, which permits others to distribute, remix, adapt, build upon this work non-commercially, and license their derivative works on different terms, provided the original work is properly cited, appropriate credit is given, any changes made indicated, and the use is non-commercial. See: http://creativecommons.org/licenses/by-nc/4.0/.

\section{REFERENCES}

1. World Health Organization. Preventing suicide: A global imperative. Geneva: World Health Organization, 2014.

2. India State-Level Disease Burden Initiative Suicide Collaborators. Gender differentials and state variations in suicide deaths in India: the Global Burden of Disease Study 1990-2016. Lancet Public Health 2018;3:e478-e489.

3. Armstrong G, Vijayakumar L. Suicide in India: a complex public health tragedy in need of a plan. Lancet Public Health 2018;3:e459-e460.

4. Zalsman G, Hawton K, Wasserman D, et al. Suicide prevention strategies revisited: 10-year systematic review. Lancet Psychiatry 2016;3:646-59.

5. Turecki G, Brent DA. Suicide and suicidal behaviour. Lancet 2016;387:1227-39.

6. O'Connor R, Pirkis J. The International Handbook of Suicide Prevention. 2nd Edn. United Kingdom: Wile-Blackwell, 2016.

7. Niederkrotenthaler T, Voracek M, Herberth A, et al. Role of media reports in completed and prevented suicide: Werther v. Papageno effects. Br J Psychiatry 2010;197:234-43.

8. Cheng Q, Chen F, Yip PS. Media effects on suicide methods: A case study on Hong Kong 1998-2005. PLoS One 2017;12:e0175580.

9. King KE, Schlichthorst M, Spittal MJ, et al. Can a documentary increase help-seeking intentions in men? A randomised controlled trial. J Epidemiol Community Health 2018;72:92-8.

10. Niederkrotenthaler T, Fu KW, Yip PS, et al. Changes in suicide rates following media reports on celebrity suicide: a meta-analysis. $J$ Epidemiol Community Health 2012;66:1037-42.

11. Chen YY, Chen F, Yip PS. The impact of media reporting of suicide on actual suicides in Taiwan, 2002-05. J Epidemiol Community Health 2011;65:934-40.

12. Kunrath $\mathrm{S}$, Baumert J, Ladwig $\mathrm{KH}$. Increasing railway suicide acts after media coverage of a fatal railway accident? An ecological study of 747 suicidal acts. J Epidemiol Community Health 2011;65:825-8.

13. World Health Organization, International Association for Suicide Prevention. Preventing suicide: a resource for media professionals, update. Geneva: World Health Organization, 2017.
14. Ponnudurai R. Suicide in India - changing trends and challenges ahead. Indian J Psychiatry 2015;57:348-54.

15. Armstrong G, Vijayakumar L, Niederkrotenthaler T, et al. Assessing the quality of media reporting of suicide news in India against World Health Organization guidelines: A content analysis study of nine major newspapers in Tamil Nadu. Aust N Z J Psychiatry 2018;52:856-63.

16. Shoemaker P, Cohen A. News around the world: content, practitioners, and the public. New York: Routledge, 2006.

17. Niederkrotenthaler T, Till B, Herberth A, et al. The gap between suicide characteristics in the print media and in the population. Eur $J$ Public Health 2009;19:361-4.

18. Chen YY, Yip PS, Tsai CW, et al. Media representation of gender patterns of suicide in Taiwan. Crisis 2012;33:144-50.

19. Machlin A, Pirkis J, Spittal MJ. Which suicides are reported in the media - and what makes them "newsworthy"? Crisis 2013;34:305-13.

20. Fu KW, Chan YY, Yip PS. Newspaper reporting of suicides in Hong Kong, Taiwan and Guangzhou: compliance with WHO media guidelines and epidemiological comparisons. J Epidemiol Community Health 2011;65:928-33.

21. National Crime Records Bureau. Accidental Deaths \& Suicides in IndiaNew Delhi, India: Ministry of Home Affairs, Government of India, 2015.

22. Media Research Users Council. Indian Readership Survey 2014. Mumbai, India: Media Research Users Council, 2017.

23 . Audit Bureau of Circulations. Details of most circulated publications for the audit period January - June 2014. Mumbai, India: Audit Bureau of Circulations 2015

24. Arya V, Page A, River J, et al. Trends and socio-economic determinants of suicide in India: 2001-2013. Soc Psychiatry Psychiatr Epidemiol 2018;53:269-78.

25. Bhola P, Manjula M, Rajappa V, et al. Predictors of non-suicidal and suicidal self-injurious behaviours, among adolescents and young adults in urban India. Asian J Psychiatr 2017;29:123-8.

26. Hinduism CK. Hinduism and female sexuality: Social control and education of girls in India. Sociological Bulletin 2001;50:37-63.

27. Mullaiti L. Families in India: Beliefs and Realities. J Comp Fam Stud 1995;26:11-25.

28. Kposowa AJ. Marital status and suicide in the national longitudinal mortality study. J Epidemiol Community Health 2000;54:254-61.

29. Latha KS, Bhat SM, D'Souza P. Suicide attempters in a general hospital unit in India: their socio-demographic and clinical profileemphasis on cross-cultural aspects. Acta Psychiatr Scand 1996;94:26-30.

30. Srivastava MK, Sahoo RN, Ghotekar LH, et al. Risk factors associated with attempted suicide: a case control study. Indian J Psychiatry 2004;46:33-8.

31. Mary RA, Marslin G, Franklin G, et al. Test anxiety levels of board exam going students in Tamil Nadu, India. Biomed Res Int 2014;2014:578323.

32. Kennedy J, King L. The political economy of farmers' suicides in India: indebted cash-crop farmers with marginal landholdings explain state-level variation in suicide rates. Global Health 2014;10:16.

33. MÜNSTER DN. Farmers' Suicides as Public Death: Politics, Agency and Statistics in a Suicide-Prone District (South India). Mod Asian Stud 2015;49:1580-605.

34. Spicer RS, Miller TR. Suicide acts in 8 states: incidence and case fatality rates by demographics and method. Am J Public Health 2000;90:1885-91.

35. Vijayakumar L, Jeyaseelan L, Kumar S, et al. A central storage facility to reduce pesticide suicides-a feasibility study from India. BMC Public Health 2013;13:850.

36. Gunnell D, Ho D, Murray V. Medical management of deliberate drug overdose: a neglected area for suicide prevention? Emerg Med $\mathrm{J}$ 2004;21:35-8.

37. de Silva VA, Senanayake SM, Dias P, et al. From pesticides to medicinal drugs: time series analyses of methods of self-harm in Sri Lanka. Bull World Health Organ 2012;90:40-6.

38. Till B, Wild TA, Arendt F, et al. Associations of tabloid newspaper use with endorsement of suicide myths, suicide-related knowledge, and stigmatizing attitudes toward suicidal individuals. Crisis 2018;39:428-37.

39. Jamieson $\mathrm{P}$, Jamieson $\mathrm{KH}$, Romer $\mathrm{D}$. THe responsible reporting of suicide in print journalism. Am Behav Sci 2003;46:1643-60. 